This item was submitted to Loughborough's Research Repository by the author.

Items in Figshare are protected by copyright, with all rights reserved, unless otherwise indicated.

\title{
Detecting eating psychopathology in female athletes by asking about exercise: Use of the compulsive exercise test
}

PLEASE CITE THE PUBLISHED VERSION

https://doi.org/10.1002/erv.2561

PUBLISHER

(c) Wiley

VERSION

AM (Accepted Manuscript)

\section{PUBLISHER STATEMENT}

This work is made available according to the conditions of the Creative Commons Attribution-NonCommercialNoDerivatives 4.0 International (CC BY-NC-ND 4.0) licence. Full details of this licence are available at: https://creativecommons.org/licenses/by-nc-nd/4.0/

\section{LICENCE}

CC BY-NC-ND 4.0

\section{REPOSITORY RECORD}

Plateau, Carolyn, Jon Arcelus, and Caroline Meyer. 2019. "Detecting Eating Psychopathology in Female Athletes by Asking About Exercise: Use of the Compulsive Exercise Test". figshare. https://hdl.handle.net/2134/26537. 
RUNNING HEAD: DETECTING EATING PSYCHOPATHOLOGY IN ATHLETES

Detecting eating psychopathology in female athletes by asking about exercise: Use of the

\section{Compulsive Exercise Test}

Accepted Version

Please cite this article as:

Plateau, C.R., Arcelus, J., \& Meyer, C. (in press). Detecting eating psychopathology in female athletes by asking about exercise: Use of the Compulsive Exercise Test. European

Eating Disorders Review. 


\title{
DETECTING EATING PSYCHOPATHOLOGY IN ATHLETES
}

\begin{abstract}
The present study assessed the suitability of the Compulsive Exercise Test (athlete version; CET-A) for identifying female athletes with clinically significant features related to or comparable with eating psychopathology. Three hundred and sixty-one female athletes (including 12 with a clinically diagnosed eating disorder) completed the Eating Disorders Examination Questionnaire (EDE-Q) and the CET-A. Receiver Operating Curve (ROC) analysis was employed to identify a cut-off value on the CET-A which could indicate clinically significant features related to or comparable with eating psychopathology among female athletes. The analysis demonstrated that a CET-A score of 10 successfully discriminated female athletes with a current eating disorder. The results suggest that the CET-A may be a suitable tool for detecting eating psychopathology in female athletes. Additional longitudinal research is needed to evaluate the predictive value of the CET-A.
\end{abstract} Key words: assessment, screening, sport, eating disorder, exercise 


\section{DETECTING EATING PSYCHOPATHOLOGY IN ATHLETES}

\section{Detecting eating psychopathology in female athletes by asking about exercise: Use of the \\ Compulsive Exercise Test}

Compulsive exercise can be defined as a rigid and unstoppable drive to exercise, which occurs to the exclusion of other daily activities, despite awareness of potential negative consequences (Adkins \& Keel; 2005; Taranis, Touyz \& Meyer, 2011). Whilst the frequency and duration of exercise seem to be largely unrelated to eating psychopathology (e.g., Boyd, Abraham \& Luscombe; 2007; Lipsey, Barton, Hulley \& Hill, 2006), compulsive exercise attitudes and behaviours have been identified as having an important role in the development and maintenance of eating disorders (ED; Meyer, Taranis, Goodwin \& Haycraft, 2011). Compulsive exercise attitudes and behaviours have been consistently linked with more severe presentations of eating psychopathology (e.g., Bewell-Weiss \& Carter, 2010; Noetel et al., 2016) and poorer treatment outcomes (e.g., Dalle Grave, Calugi \& Marchesini, 2008;

Danielsen, Rø, Romild \& Bjørnelv, 2016), with evidence to suggest that compulsive exercise attitudes may mediate the relationship between exercise behaviours and eating psychopathology (e.g., Cook, Hausenblas, Crosby, Cao \& Wonderlich, 2015; Mond et al., 2004).

Athletes are one particular group that has been found to present with elevated levels of eating psychopathology, with up to one in five female athletes presenting with clinically significant eating problems (Bratland-Sanda \& Sundgot-Borgen, 2013; Sundgot-Borgen \& Torstveit, 2004). Large scale prospective studies exploring trajectories of eating psychopathology and predictors of the onset of EDs in athlete populations are largely absent from the literature; although links between sports related pressures around weight and shape and disordered eating practices have been demonstrated (e.g., Anderson, Petrie \& Neumann, 2012; Krentz \& Warschburger, 2013). Cross-sectional investigations have demonstrated close links between compulsive exercise and eating psychopathology in athletes (Plateau et al., 


\section{DETECTING EATING PSYCHOPATHOLOGY IN ATHLETES}

2014), and also between compulsive exercise and other known risk factors for eating psychopathology (e.g., athletic identity, perfectionism; Egan et al., 2017; Madigan, Stoeber \& Passfield, 2017; Turton, Goodwin \& Meyer, 2017). Whilst further longitudinal research is needed to establish temporal and etiological relationships, existing evidence suggests that compulsive exercise is a relevant feature related to eating psychopathology in athletes.

The early identification and treatment of EDs is critical for successful long term recovery (Franko et al., 2013; Treasure \& Russell, 2011). Indeed, recent guidelines emphasise the importance of early identification of EDs for the protection of athlete health (Joy, Kussman \& Nattiv, 2016; Mountjoy et al., 2014). Several screening measures have been designed for use with the general population to support the identification of individuals at risk of an ED and who may require further psychological and medical examination (Morgan, Reid \& Lacey, 1999; Striegel-Moore et al., 2010). However, current guidelines for screening for EDs among athletes recommend using measures that have been specifically developed for use with this population (Bonci et al., 2008; Mountjoy et al., 2014). A number of athlete-specific screening tools have since been developed, but there is still significant variation in a) the extent to which these measures have been validated with sufficiently large and varied athlete samples; b) the ease with which such measures can be implemented within the sporting context; and c) the accuracy with which they can detect athletes who may be at risk of eating disorders (Knapp, Aemi \& Anderson, 2014; Martinsen, Holme, Pensgaard, Torstveit, \& Sundgot-Borgen, 2014; Pope, Gao, Bolter \& Pritchard, 2015; Wagner, Erickson, Tierney, Houston \& Bacon, 2016).

Indeed, there is evidence to suggest that athletes significantly underreport eating psychopathology on self-report questionnaires, due to concerns over potential restrictions to training and competition, a loss of scholarships or governing body funding, or concerns over the perceived stigma of mental illness (Gulliver, Griffiths \& Christensen, 2012; Martinsen \& 


\section{DETECTING EATING PSYCHOPATHOLOGY IN ATHLETES}

Sundgot-Borgen, 2013; Torstveit, Rosenvinge \& Sundgot-Borgen, 2008). The face validity of such questionnaires is often very high, with the majority having a clear focus on eating attitudes and behaviours, and which consequently may be subject to distortion (Vitousek, Daly \& Heiser, 1991). An alternative approach would involve employing screening questionnaires with lower face validity, but which can still identify signs and symptoms linked to increased levels of eating psychopathology, such as compulsive exercise attitudes and behaviours (Meyer et al., 2016; Yates, Edman, Crago \& Crowell, 2001). One such measure, which has recently been adapted for use with athletes, is the Compulsive Exercise Test (CET; Taranis, Touyz \& Meyer, 2011; CET-Athlete version; Plateau et al., 2014).

The CET was based on the cognitive-behavioural model of compulsive exercise (Meyer et al., 2011), and assesses the cognitive, behavioural and emotional aspects of exercise in relation to eating psychopathology (e.g., exercising to modify weight and shape, exercising to alleviate or avoid low mood, and continuing to exercise despite injury or illness; Taranis et al., 2011). Research has demonstrated that the CET is superior to other measures of exercise attitudes and behaviours when considering associations with eating psychopathology, among both non-clinical and clinical populations (Taranis et al., 2011; Goodwin, Haycraft, Taranis \& Meyer, 2011; Young et al., 2016), and CET scores can be used to successfully discriminate ED patients from non-patients (Meyer et al., 2016), and between ED diagnostic groups (Sauchelli et al., 2016). The athlete version of the CET (CET-A) is a shortened version of the original CET, and includes three subscales that were found to be relevant for the athlete population (Avoidance of Negative Affect; Weight Control Exercise and Mood Improvement; Plateau et al., 2014). Previous research with the CET-A has demonstrated close links between levels of compulsive exercise and eating psychopathology among athletes (Plateau et al., 2014); however, research has yet to explore the efficacy of the CET-A as a screening tool for detecting features of eating psychopathology among female athletes. 


\section{DETECTING EATING PSYCHOPATHOLOGY IN ATHLETES}

Early identification of athletes at risk of EDs is imperative given the potential detrimental impact of these disorders on both athlete health and performance (Mountjoy et al., 2014). However, there are still considerable challenges in screening for EDs among athletes, with few screening tools suitably validated for use in this group, with particular concerns around potential underreporting biases among athletes on measures that are explicitly measuring eating attitudes and behaviours (e.g., Martinsen \& Sundgot-Borgen, 2013). Consequently, there is a need for athlete-specific screening measures that are reliable and easy-to-administer within the sporting context. Previous research has demonstrated that compulsive exercise is a relevant and related feature for eating psychopathology among athletes (e.g., Plateau et al., 2014), and thus screening for features of compulsive exercise may offer a potentially useful and novel means by which to identify athletes at risk, without focusing explicitly on eating behaviours. Therefore, this study aimed to validate the athlete version of the Compulsive Exercise Test (CET-A; Plateau et al., 2014) as a screening tool for detecting features of eating psychopathology among female athletes. The study aimed to identify a score on the CET-A which could indicate clinically significant features related to and comparable with eating psychopathology among female athletes. It was hypothesised that global scores on the CET-A would sufficiently discriminate athletes with elevated levels of eating psychopathology via ROC analysis. 
DETECTING EATING PSYCHOPATHOLOGY IN ATHLETES

\section{Method}

\section{Participants and procedure}

Both institutional and National Health Service (NHS) ethical approvals were granted. Inclusion criteria specified current engagement in competitive sport and over 18 yrs of age. Three hundred and forty nine female athletes were recruited from community and university sports clubs. A further 12 athletes were recruited from NHS ED services, and were informed about the study by their clinician. Clinical participants had to be currently training or have had a history of training for a particular sport, and to have been involved in competition in that sport. Clinical participants also had to be currently receiving ED treatment (bulimia nervosa: $n=6$; anorexia nervosa: $n=3$; other specified feeding or eating disorder: $n=3$ ). Mean length of symptoms was 7.50yrs $(S D=7.82)$. Seven of the clinical participants participated in 'lean’ sports (e.g., distance running, gymnastics), whilst the remainder participated in non-lean sports (e.g., hockey, throwing). Nine participants reported competing at regional level or above, whilst the remainder competed at club level. The clinical participants had a mean age of 24.23yrs $\left(S D=8.32\right.$ ) and a mean BMI of $19.27 \mathrm{~kg} / \mathrm{m}^{2}$ (range $\left.14.45-23.44 \mathrm{~kg} / \mathrm{m}^{2}\right)$.

Of the non-clinical sample, 10 participants self-reported a current ED, whilst a further 22 participants reported a previous ED. The mean age of the non-clinical sample was 23.08 $(S D=3.94)$; Mean BMI was $21.03 \mathrm{~kg} / \mathrm{m}^{2}(S D=2.42)$. Most were endurance athletes (e.g., distance running, triathlon; 58.4\%; $n=208$ ) or ball sports players (e.g., football, hockey; $22.2 \%, n=76$ ); with $69 \%$ and $31 \%$ of the sample competing in lean and non-lean sports respectively. Most athletes reported currently competing at national/international level (49.1\%); with the remainder competing for their club/county (24.4\%), or university/region (26.4\%\%). Informed consent was obtained from participants before they took part in the study. Participants completed the following measures. 
DETECTING EATING PSYCHOPATHOLOGY IN ATHLETES

\section{Materials}

The Compulsive Exercise Test - Athlete version (CET-A; Plateau et al., 2014). The athlete version of the Compulsive Exercise Test has been adapted from the Compulsive Exercise Test (Taranis et al., 2011), and assesses the cognitive behavioural components of exercise in relation to disordered eating (Taranis et al., 2011). The CET-A includes 15-items, which are scored on a 6 point Likert scale from "Never True" to "Always True". The measure consists of three subscales (Avoidance of Negative Affect, Weight Control Exercise and Mood Improvement). The mean scores of the subscales are summed to create a global score. In this study, CET-A subscale $\alpha$ values ranged between .72 and .91 .

\section{The Eating Disorders Examination Questionnaire (EDE-Q; Fairburn \& Beglin,} 2008). The EDE-Q assesses eating psychopathology cognitions and behaviours over the preceding 28-day period. The measure has been previously been used to assess eating psychopathology among athletes, demonstrating good internal reliability (e.g., Hulley, Currie, Njenga \& Hill, 2007; Shanmugam, Jowett, \& Meyer, 2012). Here, EDE-Q subscale $\alpha$ values ranged from .85-.94.

\section{Data analysis}

Non-parametric tests were employed where possible to account for group size differences and non-normal EDE-Q data. First, preliminary Kruskal Wallis tests of difference were conducted to compare CET-A and EDE-Q scores among previous, current and no reported ED groups. Participants with both self-reported and clinically confirmed EDs (current and previous) were retained in the sample at this stage, resulting in 22 participants with a current ED, 22 participants with a previous ED, and 317 participants with no reported ED. 


\section{DETECTING EATING PSYCHOPATHOLOGY IN ATHLETES}

Receiver operating curve (ROC) analysis was employed to assess the suitability of the CET-A for identifying female athletes with clinically significant features related to eating psychopathology. Athletes who self-reported a current or previous ED via the online questionnaire $(n=32)$ were not included in this analysis to ensure that only current cases and non-cases were compared; twelve confirmed ED cases and 317 non-cases were included. ROC analysis is a commonly utilised approach for discriminating between two patient states (usually those who have a specific condition, versus those who do not), based on the outcome from one measure (Metz, 1978). It is a technique that is used widely across clinical epidemiological settings, and has previously been used in developing and evaluating ED screening measures, using similar sample sizes of diagnosed cases to establish validity and to identify appropriate cut off scores (e.g., Mond et al., 2008; Mustelin, Karkkainen, Kapiro \& Keski-Rahkonen, 2016). Sensitivity and specificity values were evaluated to support the identification of a suitable CET-A score that could facilitate the identification of athletes with elevated levels of eating psychopathology. Critical scores of above 70\% for sensitivity and specificity are deemed acceptable, although scores above $80 \%$ are optimal (Dovey, Aldridge, Martin, Wilken \& Meyer, 2016; Mond et al., 2008). In addition, an area under the curve (AUC) and positive predictive value analysis was included. Finally, the characteristics of athletes scoring positive (above the proposed cut off score) and negative (below the proposed cut off score) were explored, and comparisons with the clinical sample were investigated. A $p$ value of $<.01$ was employed throughout. The analysis was conducted in SPSS v21.0. 
DETECTING EATING PSYCHOPATHOLOGY IN ATHLETES

\section{Results}

\section{Characteristics of the sample}

Preliminary Kruskal-Wallis analysis revealed that scores on the EDE-Q subscales and the CET-A Avoidance, Weight Control Exercise and Global subscales were significantly higher for the current $(n=22)$ and previous ED $(n=22)$ groups compared to those with no reported ED. The previous ED group also scored significantly higher than those with no reported ED on CET-A Mood Improvement. No differences were observed between the current and previous ED groups on either measure or for age and BMI (see Table 1). The mean EDE-Q scores are slightly higher than have previously been reported within the athlete literature (e.g., Hulley \& Hill, 2001; Shanmugam et al., 2012); but in line with norms for community and clinical samples respectively (e.g., Aardoorm, Dingemans, Slof Op’t Landt \& Van Furth, 2012; Mond et al., 2004).

\section{Establishing a cut off score}

Three hundred and twenty nine female athletes (including 12 with a confirmed ED) were included in the ROC analysis. Global scores on the CET-A were analysed against eating disorder status, and revealed a significant area under the curve: Area $(\mathrm{SE})=.87(0.03)$ $p<.01$; [95\% CI: 0.81-0.93]. Table 2 indicates the sensitivity and the specificity across different Global CET-A scores. Researchers may be required to compromise between sensitivity and specificity values when determining appropriate cut off scores (e.g., Meyer et al., 2016). Sensitivity of the proposed cut-off score is often given precedence when developing new screening tools. This can help to ensure that all true cases are identified (e.g., Steinsbekk, Sveen, Fildes, Llewellyn \& Wichstrom, 2017; Warner, 2004). As shown in Table 2, lower scores on the CET-A were associated with higher sensitivity, but the specificity of the measure was poor; and below the 70\% critical score (Dovey et al., 2016; 


\section{DETECTING EATING PSYCHOPATHOLOGY IN ATHLETES}

Mond et al., 2008). Thus, a trade-off between sensitivity and specificity was deemed to be most appropriate, and a Global CET-A score of 10 represented suitable levels of both sensitivity (.92) and specificity (.73). Employing a score of 10 as a cut off resulted in one true positive case screening negative. Further assessment of this case revealed a CET-A Global Score of 9.78.

\section{Characteristics of participants screening positive and negative}

Participants who screened positive according to the proposed cut off ( $\geq 10$ Global Score CET-A; $n=100$ ) scored significantly higher on the EDE-Q and CET-A subscales than those screening negative $(<10 ; n=229$; Table 3$)$. The groups did not differ on either age or BMI. Positive screen scores were recorded by $39.7 \%$ of lean athletes and $25.9 \%$ of non-lean athletes; however competitive level and sport type were found to be unrelated to screen status $\left[\chi^{2}(2)=.97, p=.62 ; \chi^{2}(1)=6.40, p=.02\right.$, respectively $]$. Participants screening positive on the CET-A were significantly more likely to have an ED in comparison to those screening negative (Relative Risk $=3.24, p<.01,[95 \% \mathrm{CI}=2.51-4.19])$.

Further comparisons were conducted between the clinical cases $(n=12)$ and the participants screening positive $(n=89)$. Mann-Whitney U analyses indicated that significant differences between the groups were only apparent for the Eating Concern subscale of the EDE-Q, with the clinical group scoring significantly higher $(\mathrm{Z}=.35(r=.35), p<0.01$; see

Table 4). No differences in sport type or competitive level were observed. 


\section{DETECTING EATING PSYCHOPATHOLOGY IN ATHLETES}

\section{Discussion}

This study adopted a novel approach to screening for eating psychopathology among female athletes, by considering the suitability of an exercise based screening tool. The ability of the CET-A to detect female athletes with elevated levels of eating psychopathology was evaluated. The analysis revealed that a Global Score of 10 on the CET-A might be a suitable cut off for identifying those with clinically significant features related to and comparable with eating psychopathology. There were no other characteristics (e.g., age, BMI, sport-type, competitive level) that differentiated athletes who screened positive or negative on the CETA. This study takes an important step towards validating a novel, exercise-based screening tool for detecting eating psychopathology among athletes.

Using the proposed cut off score on the CET-A, 92\% of female athletes with a confirmed ED could be identified. This is similar or superior to screening tools used to detect those at risk of eating disorders among the general population (Mond et al., 2004; Morgan et al., 1999; Mustelin et al., 2016). In line with guidance for developing screening tools, the sensitivity of the measure was prioritised (Warner 2004), and consequently a number of noncases also scored above the cut-off criteria. However, further analysis indicated that those screening positive reported significantly higher levels of eating psychopathology than those screening negative. Notably, the mean EDE-Q global score for the positive screen group was above the recommended cut-off for identifying ED cases in the community (Mond et al., 2004). In addition, differences in levels of eating psychopathology for those with a diagnosed ED in comparison to the positive screen group were only apparent for the Eating Concern subscale of the EDE-Q. This provides support for the CET-A as a potentially useful screening tool for identifying eating psychopathology among female athletes. Whilst establishing temporal and etiological relationships between compulsive exercise and eating psychopathology are a key priority of future research, a screening measure with low face 


\section{DETECTING EATING PSYCHOPATHOLOGY IN ATHLETES}

validity may be particularly valuable for detecting eating psychopathology among athletes, and further work should explore biases in responding on the CET-A in comparison to other measures. It is important to note, however, that whilst compulsive exercise is commonly observed across all ED diagnostic categories (Shroff et al., 2006), it is not yet included in diagnostic criteria (DSM-5; APA, 2013) and as such, it is possible that some athletes will not exercise in a rigid or driven way despite elevated levels of eating psychopathology.

Moreover, it is plausible to suggest that features of compulsivity may be adaptive among sports participants. Success in sport requires a high degree of commitment, selfcontrol, adherence to routine and the ability to withstand and manage stress and pressure (Galli \& Gonzalez, 2015; Thompson \& Sherman, 1999). Compulsivity towards exercise and training may therefore be adaptive in terms of achieving such sporting success. Indeed, among adolescents, higher levels of compulsivity towards exercise have been observed among sports participants compared to non-sports participants, but this was not associated with increases in eating psychopathology (Goodwin, Haycraft \& Meyer, 2016). However, it also possible that high levels of compulsive exercise (e.g., continuing to exercise despite significant illness or injury, feeling extremely guilty when exercise is missed; exercising primarily to alter weight and shape) could precipitate more severe clinical conditions (Meyer et al. 2011). Further prospective research is needed to explore longitudinal relationships between compulsive exercise cognitions and disordered eating among sports participants.

Nevertheless, elevated levels of eating psychopathology and compulsive exercise were discovered for athletes reporting a previous or current ED compared to those with no reported ED, with these athletes group scoring particularly highly on the Avoidance of Negative Affect and Weight Control Exercise facets of compulsive exercise. These components have been identified as key distinguishing features of ED patients from nonpatients (Meyer et al., 2016). Notably, neither sport-type nor level of competition were 


\section{DETECTING EATING PSYCHOPATHOLOGY IN ATHLETES}

significantly associated with screen status. These findings suggest that compulsive exercise attitudes and behaviours occur across all levels of competition and regardless of sporting discipline. Existing evidence has identified elements of the sporting context that can elicit, trigger or even protect against eating psychopathology among athletes (e.g., Bratland-Sanda \& Sundgot-Borgen, 2013). However, the present findings suggest that athlete motives and beliefs around exercise may be particularly important when considering their risk of an ED, and targeting prevention efforts towards athletes with these features may be more effective than targeting athletes of particular sports types or competitive level (Papathomas \& Lavallee, 2012).

It is important to acknowledge that there are limitations to using a statistical approach (ROC analysis) to determine suitable cut off scores on a new screening tool. In particular, prioritising sensitivity over specificity will likely lead to an increased number of false positive outcomes (Metz, 1978), and thus the potential for some individuals who screen positive to be referred for further evaluation that is unnecessary. However, prioritising sensitivity will also reduce the likelihood of missing potential cases (false negatives). Therefore, the proposed cut off needs to be utilised with caution and athletes presenting with problematic eating or exercise practices should be recommended for further evaluation, irrespective of their CET-A score.

In addition, the study included only a small number of confirmed ED cases, who showed considerable heterogeneity in terms of their sporting background. The study also focused only on female athletes, and adopted a self-report methodology. Future studies should incorporate a larger, more homogenous clinical sample, and explore the suitability of the cut off by diagnostic group. For example, there is some evidence to suggest that CET scores may be elevated among bulimia nervosa $(\mathrm{BN})$ and residual category eating disorders in comparison to anorexia nervosa (AN) patients (Sauchelli et al., 2016). In addition, future 


\section{DETECTING EATING PSYCHOPATHOLOGY IN ATHLETES}

studies should look to include a clinical interview for all participants to verify eating disorder status (Eating Disorders Examination; Fairburn \& Cooper, 1993). An important next step is to prospectively validate the screening tool and the proposed cut-off, with a diverse sample of male and female athletes. Finally, whilst the identification of athletes with high levels of compulsive exercise and associated eating psychopathology is an important first step, challenges still remain for clinicians in identifying and addressing potentially unhealthy exercise among competitive athletes. Indeed, athletes may require specifically tailored interventions to support the development of a healthier relationship with exercise (Noetel et al., 2017). At present, no such exercise focused interventions for athletes are known to have been developed or evaluated.

Despite these limitations, the study has important clinical relevance. The early detection of eating problems among athletes has been identified as being of critical importance to protect their physical and psychological wellbeing (Mountjoy et al., 2014). An athlete specific, valid screening tool such as the CET-A is likely to be important in expediting the detection of potential eating and exercise issues among athletes, and potentially preventing problems from escalating further. For example, the tool may be particularly useful for sports professionals, who often struggle to identify potential eating problems among athletes (Nowicka, Eli, Ng, Apitzsch, \& Sundgot-Borgen, 2013; Plateau, McDermott, Arcelus \& Meyer, 2014). Athletes are often unwilling to disclose an eating problem due to concerns about being prevented from training, potential loss of funding or sponsorship, or the perceived stigma of having a mental health issue (Gulliver et al., 2012). Eating disorders are also typically characterized by significant secrecy and denial (Vandereycken \& Humbeeck, 2008); hence the detection of these issues in athletes can be particularly challenging. The ability of the measure to successfully detect female athletes with elevated levels of eating psychopathology without explicitly asking about eating behavior could be an important 


\section{DETECTING EATING PSYCHOPATHOLOGY IN ATHLETES}

strength of the CET-A, due to the underreporting biases that are commonly observed for eating related measures in this group (e.g., Martinsen \& Sundgot-Borgen, 2013). Further research is needed to improve our understanding of potential reporting biases in athletes, and prospective studies with the CET-A are required to determine the predictive ability of measure in wider athlete and clinical samples. However, this study represents an important first step towards validating an athlete-specific screening tool.

In summary, this study adopts a novel approach to identifying eating psychopathology in female athletes, by considering the suitability of an exercise focused screening tool in detecting athletes with elevated levels of eating psychopathology. The findings indicate that the CET-A could be helpful tool for use within the sport context to support the identification of female athletes who may require further assessment and support to develop a healthier relationship with exercise. This study takes an important step towards validating an exercise based tool for detecting eating psychopathology among athletes, utilising a gold standard analytic approach to identify an appropriate cut off score on the CET-A. Further longitudinal assessment of the measure is required in order to assess the predictive validity of the proposed cut-off. 
DETECTING EATING PSYCHOPATHOLOGY IN ATHLETES

\section{References}

Aardoorm, J.J., Dingemans, A.E., Slof Op’t Landt, M.C.T., \& Van Furth, E.F. (2012). Norms and discriminative validity of the Eating Disorder Examination Questionnaire (EDE-Q). Eating Behaviors, 13(4), 305-309. DOI:10.1016/j.eatbeh.2012.09.002

Adkins, E.C., \& Keel, P.K. (2005). Does ‘excessive’ or ‘compulsive’ best describe exercise as a symptom of bulimia nervosa? International Journal of Eating Disorders, 38(1), 24-29. DOI: 10.1002/eat.20140

American Psychiatric Association. (2013). Diagnostic and statistical manual of mental disorders (5th ed.). Washington, DC: Author.

Anderson, C.M., Petrie, T.M., \& Neumann, C.S (2012). Effects of sport pressures on female collegiate athletes: A preliminary longitudinal investigation. Sport, Exercise and Performance Psychology, 1(2), 120-134. DOI: 10.1037/a0026587

Bewell-Weiss, C.V., \& Carter, J.C. (2010). Predictors of excessive exercise in anorexia nervosa. Comprehensive Psychiatry, 51(6), 566-571. DOI:

10.1016/j.comppsych.2010.03.002.

Bratland-Sanda, S., \& Sundgot-Borgen, J. (2013). Eating disorders in athletes: Overview of prevalence, risk factors and recommendations for prevention and treatment. European Journal of Sports Science,13, 499-508. DOI: 10.1080/17461391.2012.740504

Bonci, C.M., Bonci, L.J., Granger, L.R., Johnson, C.L., Malina, R.M., Milne, L.W... \& Vanderbunt, E.M. (2008). National Athletic Trainers’ Association position statement: Preventing, detecting and managing disordered eating in athletes. Journal of Athletic Training, 43(1), 80-108. DOI: 10.4085/1062-6050-43.1.80.

Boyd, C., Abraham, S., \& Luscombe, G. (2007). Exercise behaviours and feelings in eating disorder and non-eating disorder groups. European Eating Disorders Review, 15(2), 112-118. DOI:10.1002/erv.769. 


\section{DETECTING EATING PSYCHOPATHOLOGY IN ATHLETES}

Cook, B., Hausenblas, H., Crosby, R.D., Cao, L., \& Wonderlich, S.A. (2015). Exercise dependence as a mediator of the exercise and eating disorders relationship: A pilot study. Eating Behaviors, 16, 9-12. DOI: 10.1016/j.eatbeh.2014.10.012.

Dalle Grave, R., Calugi, S., \& Marchesini, G. (2008). Compulsive exercise to control shape or weight in eating disorders: Prevalence, associated features and treatment outcome. Comprehensive Psychiatry, 49, 346-352. DOI: 10.1016/j.comppsych.2007.12.007

Danielsen, M., Rø, Ø., Romild, U., \& Bjørnelv, S. (2016). Impact of female adult eating disorder inpatients' attitudes to compulsive exercise on outcome at discharge and follow-up. Journal of Eating Disorders, 4, 7. DOI: 10.1186/s40337-016-0096-0.

Davis, C., Kennedy, S.H., Ravelski, E., \& Dionne, M. (1994). The role of physical activity in the development and maintenance of eating disorders. Psychological Medicine, 24, 957-967. DOI: 10.1017/S0033291700029044

Dovey, T.M., Aldridge, V.K., Martin, C.I., Wilken, M., \& Meyer, C. (2016). Screening Avoidant/Restrictive Food Intake Disorder (ARFID) in children: Outcomes from utilitarian versus specialist psychometrics. Eating Behaviors, 23, 162-167. DOI: 10.1016/j.eatbeh.2016.10.004.

Egan, S.J., Bodill, K., Watson, H.J., Valentine, E., Shu, C., \& Hagger, M.S. (2017).

Compulsive exercise as a mediator between clinical perfectionism and eating pathology. Eating Behaviors, 24, 11-16. DOI: 10.1016/j.eatbeh.2016.11.001.

Fairburn, C.G., \& Cooper, Z. (1993). The eating disorder examination (12 ${ }^{\text {th }}$ edition). In C.G. Fairburn, \& G. T. Wilson (Eds.) Binge eating: Nature, assessment and treatment (pp. 317-360). New York: Guilford Press.

Fairburn, C.G., \& Beglin, S.J. (2008). Eating Disorder Examination Questionnaire (EDE-Q 6.0) In: Fairburn CG, editor. Cognitive behavior therapy and eating disorders. New York: Guildford Press 


\section{DETECTING EATING PSYCHOPATHOLOGY IN ATHLETES}

Franko, D., Keshaviah, A., Eddy, K.T., Krishna, M., Davis, M.C., Keel, P.K., \& Herzog, D.B. (2013). A longitudinal investigation of mortality in Anorexia Nervosa and Bulimia Nervosa. American Journal of Psychiatry, 170, 917-925. DOI: 10.1176/appi.ajp.2013.12070868

Galli, N., \& Gonzalez, S.P. (2015). Psychological resilience in sport: A review of the literature and implications for research and practice. International Journal of Sport and Exercise Psychology, 13(3), 243-257. DOI: 10.1080/1612197X.2014.946947

Goodwin, H., Haycraft, E., Meyer, C. (2016). Disordered eating, compulsive exercise and sport participation in a UK adolescent sample. European Eating Disorders Review, 24, 304-309. DOI: 10.1002/erv.2441

Goodwin, H., Haycraft, E., Taranis, L., \& Meyer, C. (2011). Psychometric evaluation of the compulsive exercise test (CET) in an adolescent population: Links with eating psychopathology. European Eating Disorders Review, 19, 269-279. DOI: 10.1002/erv.1109.

Gulliver, A., Griffiths, K.M., \& Christensen, H. (2012). Perceived barriers and facilitators to mental health help-seeking in young people: A systematic review. BMC Psychiatry, 10, 113. DOI:10.1186/1471-244X-10-113

Hulley, A., Currie, C., Njenga, F., \& Hill, A. (2007). Eating disorders in elite female distance runners: Effects of nationality and running environment. Psychology of Sport and Exercise, 8(4), 521-533. DOI: 10.1016/j.psychsport.2006.07.001

Hulley, A., \& Hill, A. (2001). Eating disorders and health in elite women distance runners. International Journal of Eating Disorders, 30(3), 312-317. DOI: 10.1002/eat.1090.

Joy, E., Kussman, E., \& Nattiv, A. (2016). 2016 update on eating disorders in athletes: A comprehensive narrative review with a focus on clinical assessment and management. British Journal of Sports Medicine, 50, 154-162. DOI: 10.1136/bjsports-2015-095735 


\section{DETECTING EATING PSYCHOPATHOLOGY IN ATHLETES}

Knapp, J., Aerni, G., \& Anderson, J. (2014). Eating disorders in female athletes: Use of screening tools. Current Sports Medicine Reports, 13(4), 214-218. DOI: 10.1249/JSR.0000000000000074.

Krentz, E.M., \& Warschburger, P. (2013). A longitudinal investigation of sports-related risk factors for disordered eating in aesthetic sports. Scandinavian Journal of Medicine and Science in Sports, 23(3), 303-310. DOI: 10.1111/j.1600-0838.2011.01380.x

Lipsey, Z., Barton, S.B., Hulley, A., \& Hill, A.J. (2006). “After a workout...” Beliefs about exercise, eating and appearance in female exercisers with and without eating disorder features. Psychology of Sport and Exercise, 7(5), 425-436. DOI:

10.1016/j.psychsport.2006.01.005

Madigan, D.J., Stoeber, J., \& Passfield, L. (2017). Athletes’ perfectionism and reasons for training: Perfectionistic concerns predict training for weight control. Personality and Individual Differences, 115, 133-136. DOI: 10.1016/j.paid.2016.03.034

Martinsen, M., Holme, I., Pensgaard, A.M., Torstveit, M.K., \& Sundgot-Borgen, J. (2014).The development of the brief eating disorder in athletes questionnaire. Medicine and Science in Sport and Exercise, 46, 1666-75. DOI:

10.1249/MSS.0000000000000276

Martinsen, M., \& Sundgot-Borgen, J. (2013). Higher prevalence of eating disorders among adolescent elite athletes than controls. Medicine and Science in Sports and Exercise, 45(6), 1188-1197 DOI: 10.1249/MSS.0b013e318281a939.

Metz, C.E. (1978). Basic principles of ROC analysis. Seminars in Nuclear Medicine, 8, 283298. DOI: 10.1016/S0001-2998(78)80014-2

Meyer, C., Plateau, C.R., Taranis, L., Brewin, N., Wales, J., Arcelus, J. (2016). The Compulsive Exercise Test: Confirmatory factor analysis and links with eating 


\section{DETECTING EATING PSYCHOPATHOLOGY IN ATHLETES}

psychopathology among women with clinical eating disorders. Journal of Eating Disorders 4:22. DOI: 10.1186/s40337-016-0113-3

Meyer, C., Taranis, L., Goodwin, H., \& Haycraft, E. (2011). Compulsive exercise and eating disorders. European Eating Disorders Review, 19, 174-189. DOI: 10.1002/erv.1122

Mond, J.M., Hay, P.J., Rodgers, B., Owen, C., \& Beumont, P.J.V. (2004). Validity of the Eating Disorders Examination Questionnaire (EDE-Q) in screening for eating disorders in community samples. Behavior Research and Therapy, 42, 551-567. DOI: 10.1016/S0005-7967(03)00161-X

Mond, J.M., Myers, T.C., Crosby, R.D., Hay, P.J., Rodgers, B., Morgan, J.F...\& Mitchell, J.E. (2008). Screening for eating disorders in primary care: EDE-Q versus the SCOFF. Behavior Research and Therapy, 46, 612-622. DOI: 10.1016/j.brat.2008.02.003

Morgan. J.F., Reid, F., \& Lacey, J.H. (1999). The SCOFF questionnaire: assessment of a new screening tool for eating disorders. BMJ, 319: 1467. DOI: 10.1136/bmj.319.7223.1467. Mountjoy, M., Sundgot-Borgen, J., Burke, L., Carter, S., Constantini, N., Lebrun, C... \& Ljungqvist, A. (2014). The IOC consensus statement: beyond the Female Athlete Triad - Relative Energy Deficiency in Sport. British Journal of Sports Medicine, 48, 491-497. DOI: 10.1136/bjsports-2014-093502

Mustelin, L., Karkkainen, U., Kapiro, J., \& Keski-Rahkonen, A. (2016). The Eating Disorder Inventory in the screening for DSM-5 binge eating disorder. Eating Behaviors, 22, 145148. DOI: 10.1016/j.eatbeh.2016.06.011.

Noetel, M., Miskovic-Wheatley, J., Crosby, R.D., Hay, P., Madden, S., \& Touyz, S. (2016). A clinical profile of compulsive exercise in adolescent inpatients with anorexia nervosa. Journal of Eating Disorders, 4:1. 


\section{DETECTING EATING PSYCHOPATHOLOGY IN ATHLETES}

Noetel, M., Dawson, L., Hay, P., \& Touyz, S. (2017). The assessment and treatment of unhealthy exercise in adolescents with anorexia nervosa: A Delphi study to synthesize clinical knowledge. International Journal of Eating Disorders. DOI: 10.1002/eat.22657.

Nowicka, P., Eli, K., Ng, J., Apitzsch, E., \& Sundgot-Borgen, J. (2013). Moving from knowledge to action: a qualitative study of elite coaches' capacity for early intervention in cases of eating disorders. International Journal Sports Science \& Coaching, 8(2) 343-355. Doi: 10.1260/1747-9541.8.2.343

Papathomas, A., \& Lavallee, D. (2012). Eating disorders in sport: A call for methodological diversity. Revisita de Psicologia del Deporte, 21(2), 387-392.

Plateau, C.R., McDermott, H.J., Arcelus, J., \& Meyer, C. (2014). Identifying and preventing disordered eating among athletes: Perceptions of track and field coaches. Psychology of Sport and Exercise, 15(6), 721-728. Doi: 10.1016/j.psychsport.2013.11.004

Plateau, CR, Shanmugam V, Duckham RL, Goodwin H, Jowett S, Brooke-Wavell KSF... \& Meyer, C. (2014). Use of the Compulsive Exercise Test with Athletes: Norms and links with eating psychopathology. Journal of Applied Sport Psychology, 26, 287-301. DOI: $10.1080 / 10413200.2013 .867911$

Pope, Z., Gao, Y., Bolter, N., \& Pritchard, M. (2015). Validity and reliability of eating disorder assessments used with athletes: A review. Journal of Sport and Health Science, 4(3), 211-221. DOI: 10.1016/j.jshs.2014.05.001.

Sauchelli, S., Arcelus, J., Granero, R., Jimenez-Murcia, S., Aguera, Z., Del Pino-Gitierrez, A., \& Fernandez-Aranda, F. (2016). Dimensions of compulsive exercise across Eating Disorder diagnostic subtypes and the validation of the Spanish version of the Compulsive Exercise Test. Frontiers in Psychology, 7, 1852. Doi: 10.3389/fpsyg.2016.01852. 


\section{DETECTING EATING PSYCHOPATHOLOGY IN ATHLETES}

Shanmugam, V., Jowett, S., \& Meyer, C. (2012). Eating psychopathology amongst athletes: Links to current attachment styles. Eating Behaviors, 13(1), 5-12. DOI: 10.1016/j.eatbeh.2011.09.004

Shroff, H., Reba, L., Thornton, M.L., Tozzi, F., Klump, K.L., Berrettini, W.H...\& Bulik, C. (2006). Features associated with excessive exercise in women with eating disorders. International Journal of Eating Disorders, 39(6), 454-461. DOI: 10.1002.eat.20247.

Steinsbekk, S., Sveen, T.H., Fildes, A., Llewellyn, C., \& Wichstrom, L. (2017). Screening for pickiness - A validation study. International Journal of Behavioral Nutrition and Physical Activity, 14(2). DOI: 10.1186/s12966-016-0458-7

Striegel-Moore, R.H., Perrin, N., DeBar, L., Wilson, G.T., Rosselli, F., \& Kraemer, H.C. (2010). Screening for binge eating disorders using the patient health questionnaire in a community sample. International Journal of Eating Disorders, 43(4), 337-343. DOI: 10.1002/eat.20694.

Sundgot-Borgen, J., \& Torstveit, M.K. (2004). Prevalence of eating disorders in elite athletes is higher than in the general population. Clinical Journal of Sports Medicine, 14(1), 2532.

Taranis, L, Touyz S, \& Meyer, C. (2011). Disordered eating and exercise: Development and preliminary validation of the Compulsive Exercise Test (CET). European Eating Disorders Review, 19, 256-268. DOI: 10.1002/erv.1108

Thompson, R.A., \& Sherman, R.T. (1999). “Good athlete” traits and characteristics of anorexia nervosa: Are they similar? Eating Disorders: The Journal of Treatment and Prevention, 7 (3), 181-190. DOI: 10.1080/10640269908249284

Torstveit, M.K., Rosenvinge, J.H., \& Sundgot-Borgen, J. (2008). Prevalence of eating disorders and the predictive power of risk models in female elite athletes: A controlled 


\section{DETECTING EATING PSYCHOPATHOLOGY IN ATHLETES}

study. Scandinavian Journal of Medicine and Science in Sports, 18,108-118. DOI: 10.1111/j.1600-0838.2007.00657.x

Treasure, J., Russell, G. (2011). The case for early intervention in anorexia nervosa: Theoretical exploration of maintaining factors. British Journal of Psychiatry, 199(1), 57. DOI: 10.1192/bjp.bp.110.087585.

Turton, R., Goodwin, H., \& Meyer, C. (2017). Athletic identity, compulsive exercise and eating psychopathology in long distance runners. Eating Behaviors, 8, 129-132. DOI: 10.1016/j.eatbeh.2017.03.001

Vandereycken, W., \& Humbeeck, I. (2008). Denial and concealment of eating disorders: A retrospective survey. European Eating Disorders Review, 16(2), 109-114. Doi: 10.1002/erv.857.

Vitousek, K.B., Daly, J., \& Heiser, C. (1991). Reconstructing the internal world of the eatingdisordered individual: Overcoming denial and distortion. International Journal of Eating Disorders, 10, 647-666. DOI: 10.1002/1098-108X(199111)10:6<647::AIDEAT2260100604>3.0.CO;2-T

Wagner, A.J., Erickson, C.D., Tierney, D.K., Houston, M.N., \& Bacon, C.E.W. (2016). The diagnostic accuracy of screening tools to detect eating disorders in female athletes. Journal of Sport Rehabilitation, 25, 395-398. DOI: 10.1123/jsr.2014-0337.

Warner, J. (2004). Clinicians’ guide to evaluating diagnostic and screening tests in psychiatry. Advances in Psychiatric Treament, 10, 446-454. DOI: 10.1192/apt.10.6.446

Yates, A., Edman, J.D., Crago, M., \& Crowell, D. (2001). Using an exercise-based instrument to detect signs of an eating disorder. Psychiatry Research, 105, 231-241. DOI: 10.1016/S0165-1781(01)00341-9

Young, S., Touyz, S., Meyer, C., Arcelus, J., Rhodes, P., Madden, S., Pike, K., Attia, E., Crosby, R.D., Wales, J., \& Hay, P. (2016). Validity of exercise measures in adults with 


\section{DETECTING EATING PSYCHOPATHOLOGY IN ATHLETES}

Anorexia Nervosa: The EDE, Compulsive Exercise Test and other self-report scales. International Journal of Eating Disorders. DOI: 10.1002/eat.22633 


\section{DETECTING EATING PSYCHOPATHOLOGY IN ATHLETES}

Table 1 Mean scores on the Eating Disorders Examination Questionnaire and the Compulsive Exercise Test for female athletes reporting a current or previous ED and those with no ED history.

\begin{tabular}{|c|c|c|c|c|c|}
\hline \multicolumn{6}{|c|}{ Mean (SD) } \\
\hline & $\begin{array}{c}\text { Current ED } \\
\text { (C) }\end{array}$ & $\begin{array}{c}\text { Previous } \\
\text { ED (P) }\end{array}$ & $\begin{array}{c}\text { No ED } \\
\text { (N) }\end{array}$ & $\begin{array}{c}\text { Kruskal } \\
\text { Wallis } \chi^{2}\end{array}$ & $\begin{array}{c}\text { Effect } \\
\text { size }\left(\eta^{2}\right)\end{array}$ \\
\hline$n$ & 22 & 22 & 317 & - & - \\
\hline Age & $23.56(6.97)$ & $23.68(3.26)$ & $23.04(3.94)$ & 3.61 & .01 \\
\hline BMI & $19.62(2.98)$ & $20.23(2.41)$ & $21.11(2.36)$ & 6.82 & .02 \\
\hline \multicolumn{6}{|l|}{ EDE-Q } \\
\hline Restraint & $3.38(1.47)$ & $3.28(1.81)$ & $1.44(1.46)$ & $42.06 * a$ & .12 \\
\hline Eating Concern & $4.00(1.23)$ & $2.93(1.88)$ & $.93(1.28)$ & $63.57 * a$ & .18 \\
\hline Shape Concern & $4.62(1.18)$ & $4.14(1.66)$ & $2.05(1.65)$ & $53.45^{* a}$ & .15 \\
\hline Weight Concern & $3.97(1.51)$ & $3.91(1.63)$ & $1.61(1.56)$ & $47.33^{* a}$ & .13 \\
\hline Global Score & $4.00(1.16)$ & $3.50(1.58)$ & $1.49(1.35)$ & $58.97 * a$ & .16 \\
\hline \multicolumn{6}{|l|}{ CET } \\
\hline Avoidance & $4.10(.96)$ & 3.98 (.69) & $2.40(1.12)$ & $60.73 * a$ & .17 \\
\hline Weight Control Exercise & $3.74(.87)$ & $3.99(.92)$ & $2.49(1.21)$ & $44.04 * a$ & .12 \\
\hline Mood Improvement & $3.90(.97)$ & $4.28(.53)$ & $3.56(.82)$ & $20.21 * \mathrm{~b}$ & .06 \\
\hline Global Score & $11.74(2.18)$ & $12.25(1.31)$ & $8.45(2.46)$ & $61.81 * a$ & .17 \\
\hline
\end{tabular}

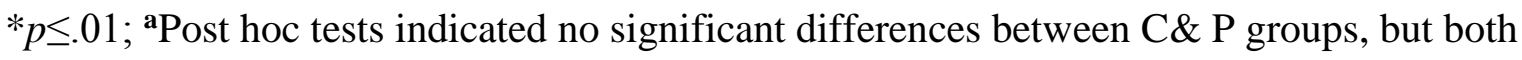

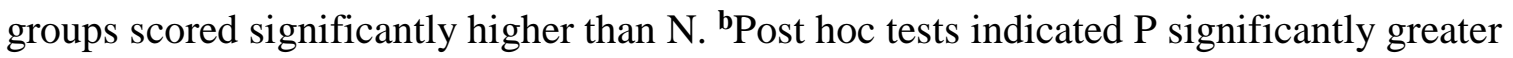
than N; no differences observed between C \& N or C \& P. 
Table 2 Sensitivity and specificity of the CET-A in distinguishing athletes with and without a current ED

\begin{tabular}{rccc}
\hline & Sensitivity & Specificity & $\begin{array}{c}\text { Positive Predictive } \\
\text { Value }\end{array}$ \\
\hline Cut off CET-A Global Score & & & \\
$\mathbf{9 . 0 0}$ & 1.00 & .60 & .09 \\
$\mathbf{9 . 5 0}$ & 1.00 & .67 & .11 \\
$\mathbf{1 0 . 0 0}$ & .92 & .73 & .12 \\
$\mathbf{1 0 . 5 0}$ & .75 & .77 & .11 \\
$\mathbf{1 1 . 0 0}$ & .58 & .81 & .11 \\
\hline
\end{tabular}




\section{DETECTING EATING PSYCHOPATHOLOGY IN ATHLETES}

Table 3 Characteristics of the groups screening positively and negatively on the CET-A when employing the proposed cut off of 10.

\section{Mean (SD)}

$\begin{array}{cccc}\text { Negative screen } & \text { Positive screen } & \begin{array}{c}\text { Mann Whitney } \\ \text { E }\end{array} & \begin{array}{c}\text { Effect } \\ (<10)\end{array} \\ & (\geq 10) & & \text { size }(r)\end{array}$

\begin{tabular}{|c|c|c|c|c|}
\hline$n$ & 229 & 100 & - & - \\
\hline Age & 23.06 (3.83) & $23.16(4.89)$ & .58 & .03 \\
\hline BMI & $21.10(2.40)$ & $20.91(2.43)$ & .46 & .03 \\
\hline \multicolumn{5}{|l|}{ EDE-Q } \\
\hline Restraint & $.97(1.10)$ & $2.69(1.55)$ & $9.26 *$ & .51 \\
\hline Eating Concern & $.57(.88)$ & $2.12(1.71)$ & 8.34* & .46 \\
\hline Shape Concern & $1.52(1.33)$ & $3.54(1.61)$ & $9.32 *$ & .51 \\
\hline Weight Concern & $1.11(1.20)$ & $2.98(1.62)$ & 9.19* & .51 \\
\hline Global Score & $1.03(.97)$ & $2.82(1.46)$ & $9.71 *$ & .54 \\
\hline \multicolumn{5}{|l|}{ CET } \\
\hline Avoidance & $1.94(.86)$ & $3.66(.83)$ & 12.13* & .67 \\
\hline Weight Control Exercise & $2.04(.99)$ & $3.65(.91)$ & $10.85^{*}$ & .60 \\
\hline Mood Improvement & $3.28(.71)$ & $4.26(.66)$ & 9.95* & .55 \\
\hline Global Score & $7.26(1.68)$ & $11.57(1.14)$ & $14.43^{*}$ & .80 \\
\hline
\end{tabular}




\section{DETECTING EATING PSYCHOPATHOLOGY IN ATHLETES}

Table 4: Characteristics of the participants screening positive on the CET-A versus those with a confirmed clinical diagnosis.

\section{Mean (SD)}

\begin{tabular}{cccc}
\hline Confirmed & Positive screen & U (Z) & size (r) \\
clinical diagnosis & CET-A & &
\end{tabular}

\section{Mann Whitney Effect} ize $(r)$ clinical diagnosis CET-A

\begin{tabular}{|c|c|c|c|c|}
\hline$n$ & 12 & 89 & - & - \\
\hline Age & $24.23(8.32)$ & 22.99 (4.23) &.-.07 & .01 \\
\hline BMI & $19.27(3.04)$ & $21.06(2.35)$ & -1.60 & .16 \\
\hline \multicolumn{5}{|l|}{ EDE-Q } \\
\hline Restraint & 3.07 & 2.65 & -.99 & .10 \\
\hline Eating Concern & 3.85 & 1.90 & $-.35^{*}$ & .35 \\
\hline Shape Concern & 4.43 & 3.42 & -2.09 & .21 \\
\hline Weight Concern & 3.57 & 2.91 & -1.38 & .14 \\
\hline Global Score & 3.73 & 2.71 & -2.48 & .25 \\
\hline \multicolumn{5}{|l|}{ CET } \\
\hline Avoidance & 4.08 & 3.59 & -1.94 & .19 \\
\hline Weight Control Exercise & 3.63 & 3.65 & -.39 & .04 \\
\hline Mood Improvement & 4.10 & 4.27 & -.46 & .05 \\
\hline Global Score & 11.81 & 11.51 & -.49 & .05 \\
\hline
\end{tabular}

